\title{
Fructose 1,6 Bisphosphate Aldolase from Gestational Diabetic Human Placenta: Purification, Identification, and Investigation of Kinetic Properties
}

\author{
Neşe Hayat Aksoy ${ }^{1,2 *}$, Pakize Dogan ${ }^{2}$ \\ ${ }^{1}$ Department of Biochemistry, Faculty of Veterinary Medicine, Aksaray University, Turkey \\ ${ }^{2}$ Department of Biochemistry, Faculty of Medicine, Hacettepe University, Turkey
}

Copyright (C) 2015 by authors, all rights reserved. Authors agree that this article remains permanently open access under the terms of the Creative Commons Attribution License 4.0 International License

\begin{abstract}
Gestational diabetes mellitus is described as glucose intolerance at various degrees that is first detected during pregnancy. In diabetic complications, there are changes in placental function, particularly with respect to intake, transmit, and utilization of glucose, and also in glycolysis and glycolytic enzymes. The placenta possibly plays a critical role in protecting the fetus from adverse effects caused by the maternal diabetic conditions. Fructose 1,6-bisphosphate aldolase, a main glycolytic enzyme, catalyses the cleavage of fructose 1,6-bisphosphate, resulting in two three-carbon products in many cells. In this study, we principally have investigated the presence of aldolase in diabetic human placenta and then purified the enzyme. We also determined the optimum conditions of enzyme assay measurements. With this procedure, we determined the specific activity of placental aldolase as $590,94 \mathrm{mU} / \mathrm{mg}$ protein, and aldolase was purified about 63,0 fold from gestational diabetic human placenta. The molecular weight of human placental aldolase was found as $160 \mathrm{kDa}$. In present study, substrate kinetics were also investigated, and two different $\mathrm{K}_{\mathrm{m}}$ and $\mathrm{V}_{\max }$ values at high and low concentrations of substrate Fructose 1,6-bisphosphate were observed. High substrate concentration range is determined as the linear substrate concentration zone. Therefore, advanced kinetic studies had been performed at this linear zone. Enzymatic assays were carried out, and substrate kinetic properties were determined. According to this determination, Vmax value of gestational diabetic placental fructose 1,6-bisphosphate aldolase was found as $939,548 \pm 60,869 \mathrm{U} / \mathrm{mg}$ and $\mathrm{Km}$ as $24,304 \pm 2,948 \mathrm{mM}$.
\end{abstract}

Keywords Fructose 1, 6 Bisphosphate Aldolase, Purification, Gestational Diabetes Mellitus, Placenta, Kinetics

\section{Introduction}

Fructose-1,6-bisphosphate

aldolase

Fru-1,6-bisphosphate D glyceraldehyde-3-P-lyase; FBPA; E.C. 4.1.2.13) catalyses the reversible cleavage of fructose-1,6-bisphosphate (FBP) to dihydroxyacetone phosphate (DHAP) and glyceraldehyde-3-phosphate (GAP) in the glycolytic pathway of prokaryotic and eukaryotic organisms. FBPA is also an essential enzyme for the reversible gluconeogenesis and the fructose metabolic pathways [1-10].

Three major tissue specific types of aldolase isozymes are known in higher organisms commonly referred to as: Type A, excreted from the classical muscle and red blood cells enzyme; Type B, from liver, kidney and small intestine; Type $\mathrm{C}$, from neuronal tissues, brain and smooth muscle [1-6,8,10-13].

Aldolases are classified as Class I and Class II aldolases depending on their requirement of divalent ions in catalysis. For their catalytic activity, Class I Aldolases do not depend on cations, and they found in higher animals and plants. Class I Aldolases form "Schiff Base" formation with the substrate and are homotetramers (40 kDa) [1-3,9]. Class II aldolases are homodimers $(80 \mathrm{kDa})$, found in bacteria and fungi, and they require a metal cofactor such as $\mathrm{Zn}^{+2}$ for catalysis [1-3,7-13].

Gestational diabetes mellitus (GDM) characterizes any degree of glucose intolerance with first recognition during pregnancy. It does not deprive the possibility that unrecognized glucose intolerance may take precedence or begin concomitantly with the pregnancy [14-21]. GDM carries a small but potentially significant risk of adverse perinatal outcomes, a long-term risk of obesity, and glucose intolerance in offspring [18-23].

The placenta is a complicated foetal organ that fulfills pleiotropic roles during fetal growth. The location between 
the two bloodstreams makes the placenta not only a crucial regulator of foetal nutrition, gas exchange, and maternal immune tolerance, but also a target for maternal and/or fetal metabolic alterations associated with pregnancy pathologies. It separates the maternal and foetal circulation, with which it is in contact through different surfaces. This organ can produce molecules that will affect mother and fetus independently [14,16,22-24].

The placenta takes a crucial role in protecting the fetus from adverse effects caused by the maternal diabetic conditions $[14,16]$. In diabetic complications, there are changes in placental function, particularly with respect to uptake, transfer, and utilization of glucose, and also in glycolysis and glycolytic enzymes. Because of this unexampled position, the placenta is subjected to the regulatory influence of hormones, cytokines, growth factors, and substrates present in both circulations and, therefore, may be affected by changes in any of these [14,16,21,23].

In diabetic gestation, maternal and foetal hyperglycaemias also influence placental metabolism, growth, and development. Diabetic insults at the beginning of gestation as in many pregestational diabetic pregnancies may have long-term effects on placental growth $[21,22,24,25]$.

The presence of FBPA in healthy human placenta is shown in the preceding study. Purification, definition, the kinetic characteristics, and properties of healthy human placental FBPA have been previously reported [26]. In this part of the study, we wanted to examine the presence and characteristics of gestational diabetic human placental FBPA. We also determined the optimum conditions (time, $\mathrm{pH}$, temperature) of enzyme assay method. Consequently, advanced kinetic researches were optimised.

\section{Materials and Methods}

\subsection{Materials}

All reagents used were of analytical grade and were obtained from Sigma Co. (St Louis, MO, USA).

\subsection{Purification Procedures}

\subsubsection{Step 1. Preparation, Extraction and Homogenization of} Tissues

Tissues were washed and perfused with cold buffer containing; 50mM Tris-HCl, $5 \mathrm{mM}$ EDTA, $4 \mathrm{mM}$ mercaptoethanol, and isotonic $\mathrm{NaCl}(0,95 \% \mathrm{ml}), \mathrm{pH}=7,5$ at $4^{\circ} \mathrm{C}$. They were weighed, minced into small pieces, and suspended in volumes $(\mathrm{v} / \mathrm{w})$ of the buffer at $+4^{\circ} \mathrm{C}$. Afterwards, the sample was homogenized for about 10 strokes by using a Teflon homogenizer in an ice bath and then centrifuged for 1 hour at $14.000 \mathrm{xg}$ and $+4^{\circ} \mathrm{C}$. The precipitate was discarded, and the clear supernatant was removed for ammonium sulphate fractionation.

\subsubsection{Step 2. Ammonium Sulphate Fractionation}

In order to obtain $45 \%$ ammonium sulphate $\left(\left(\mathrm{NH}_{4}\right)_{2} \mathrm{SO}_{4}\right)$ concentration, 26,2 $\mathrm{g}$ of solid $\left(\left(\mathrm{NH}_{4}\right)_{2} \mathrm{SO}_{4}\right)$ was added to 100 $\mathrm{ml}$ of supernatant, and it was kept for 1 hour period, then centrifuged at $14.000 \mathrm{x}$ g for 1 hour at $+4^{\circ} \mathrm{C}$. The supernatant was obtained, and the precipitate was discarded. At the second step of $\left(\left(\mathrm{NH}_{4}\right)_{2} \mathrm{SO}_{4}\right)$ fractionation $(65 \%), 12,5 \mathrm{~g}$ $\left(\left(\mathrm{NH}_{4}\right)_{2} \mathrm{SO}_{4}\right)$ was added for each $100 \mathrm{ml}$ supernatant fluid, and the procedure was repeated. This time, the supernatant was discarded, and the precipitate was collected and dissolved in $10 \mathrm{mM}$ Tris-HCl-EDTA buffer containing 1 $\mathrm{mM}$ EDTA, $\mathrm{pH}=7,5$ and any insoluble material was discarded by centrifugation.

Protein [27] and activity [28] determinations of the precipitates and supernatants were performed all along the lines of extraction and fractionation.

\subsubsection{Chromatographic Procedures}

\subsubsection{Step 3. Sephadex G-25 Gel Filtration for Desaltation}

For the desaltation, the dissolved precipitate solution which was obtained after $65 \%$ ammonium sulphate application was passed through a column of Sephadex G-25.

The column was equilibrated with running buffer. The sample volume was $20 \mathrm{ml}$, and flow rate range was $2 \mathrm{ml} / \mathrm{min}$. At the end of the application, all samples have been desalted (Data not shown).

\subsubsection{Step 4. Substrate Elution from Phosphocellulose Column}

The desalted fraction was applied to a phosphocellulose column for purification of aldolase. The fractions were absorbed at $0,5 \mathrm{ml} / \mathrm{min}$ onto a column of phosphocellulose pre-equilibrated with buffer. The column was washed with the buffer until the A280 decreased to baseline, (narrow red band visible on the column and OD of the effluent at A280 $\mathrm{nm}$ drop below 0,1 ), and then the substrate elution is carried out with stock buffer containing 2,5 mM Fru-1,6- $\mathrm{P}_{2}$. After this process, enzyme was eluted with $50 \mathrm{mM}$ Tris- $\mathrm{HCl}, 5$ mM EDTA, pH 7,5 buffer, containing $1 \mathrm{mM}$ substrate.

Protein and enzyme activity determinations were performed all along the line of gel filtration and phosphocellulose column chromatography stages.

\subsubsection{Polyacrylamide Gel Electrophoresis}

SDS-PAGE with polyacrylamide gel was performed according to the modified Laemmli method [29]. Purified enzyme was applied to SDS-PAGE electrophoresis in order to determine the molecular weight and purity. The samples were run on a 7,5\% $(\mathrm{w} / \mathrm{v})$ acrylamide separating gel and a $4,5 \%$ stacking gel. Proteins on gels were stained with Coomassie Brilliant blue R-250.

\subsubsection{Protein Determination}

Amount of the protein in the samples was determinated with Lowry Method that was slightly modificated [27]. The reactions resulted in a strong blue color, read at $750 \mathrm{~nm}$. 
Determination was run triplicate for all samples.

During the purification of FBPA procedure, protein determination was performed at $280 \mathrm{~nm}$ and corrected for nucleic acid impurities according to Warburg and Christian [30]. The A280 method takes advantage of the absorbance of light at $280 \mathrm{~nm}$ by the amino acids Tyr and Trp.

\subsubsection{Enzyme Assay}

The quantitative estimation of aldolase activity present in the extracts were determined by measuring the cleavage rate of fructose 1,6 bisphosphate spectrophotometrically. A unit of aldolase activity was defined as the amount of enzyme which catalyses the cleavage of $1 \mu$ mole of substrate per minute at $37^{\circ} \mathrm{C}$ under conditions of assay. The specific activity was defined as the number of activity units per milligram of protein. The substrate cleavage rate was determined spectrophotometrically by measuring hydrazone formation of the product with dinitrophenyl hydrazine (DNPH) [28].

\subsubsection{Kinetic Studies}

All experimental conditions were performed at $37^{\circ} \mathrm{C}$ and $\mathrm{pH} 7,4$, which were optimum enzyme assay conditions [28].
Substrate affinity constants (Km values) were determined with the Henri-Michaelis-Menten equation using a nonlinear least squares regression computer program. Substrate (fructose 1,6 bisphosphate) concentrations were selected as 0.0, 0.9, 3.0, 5.0, 7.0, 9.0 mM. Vmax (maximal reaction rate or maximal velocity at saturating substrate levels) and $\mathrm{Km}$ (Michaelis-Menten constant) constants were calculated with reciprocal Lineweaver-Burke plot of the initial velocity/substrate concentration data by the using $1 /(\mathrm{V})$ vs. $1 /(\mathrm{S})$ values [31].

\subsubsection{Statistical Analysis of Kinetic Data}

Non-linear regression analysis module of Systat 11 statistic program was used to calculate of kinetic parameters.

\section{Results}

With this modified method [32], the enzyme was purified about 63,0 fold from gestational diabetic human placenta. Elution graphic from phosphocellulose column of gestational diabetic human placental aldolase is provided at Fig. 1.

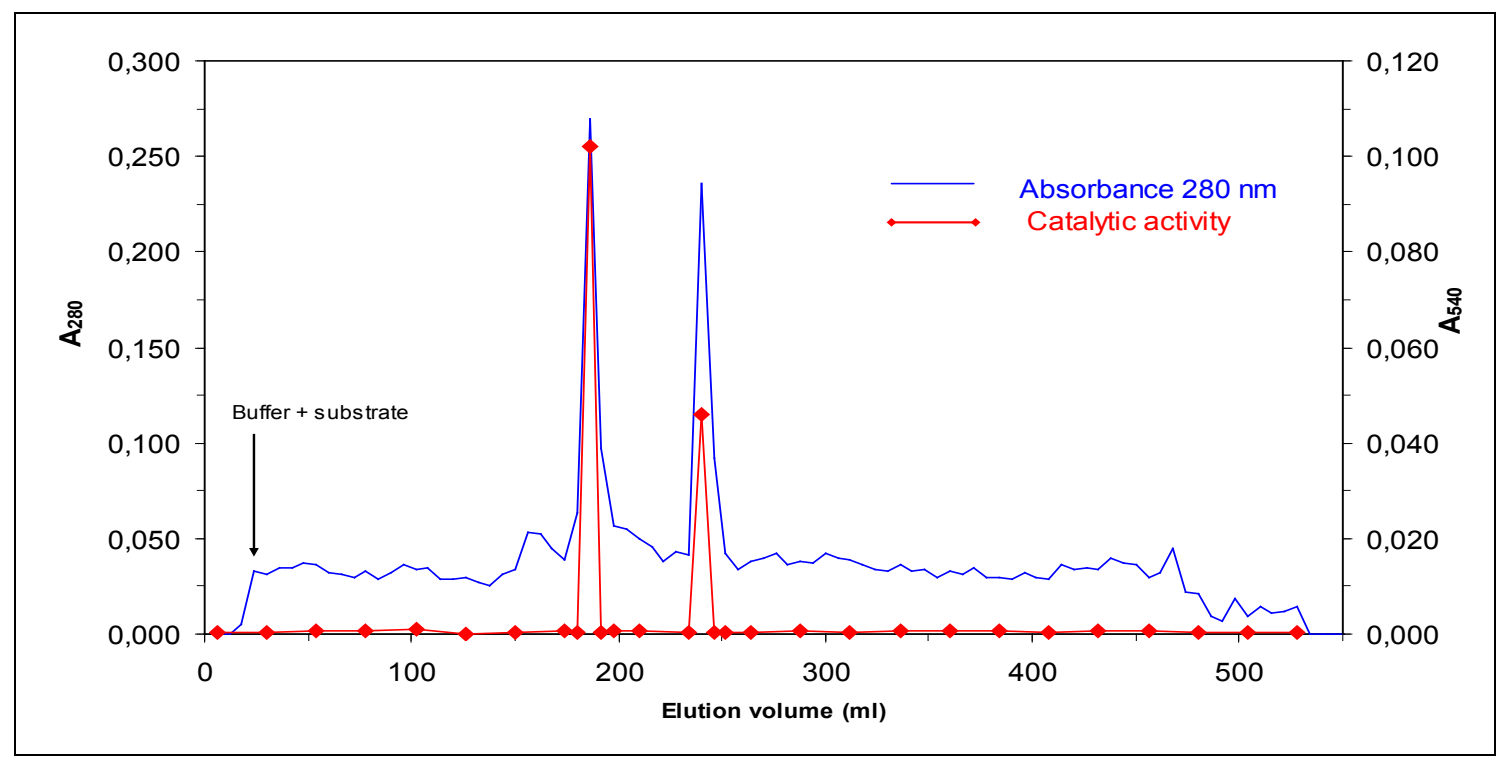

Figure 1. Elution graphic of gestational diabetic human placental aldolase

Specific activity of placental aldolase was determined as 590,94 $\mathrm{mU} / \mathrm{mg}$ protein. The summary of the purification steps are presented in Table 1.

Table 1. Purification steps of fructose 1,6 bisphosphate aldolase from gestational diabetic human placenta

\begin{tabular}{|c|c|c|c|c|c|c|}
\hline $\begin{array}{c}\text { Purification } \\
\text { Steps }\end{array}$ & $\begin{array}{c}\text { Total volume } \\
(\mathrm{ml})\end{array}$ & $\begin{array}{l}\text { Protein } \\
(\mathrm{mg} / \mathrm{ml})\end{array}$ & $\begin{array}{c}\text { Total protein } \\
\text { (mg) }\end{array}$ & $\begin{array}{l}\text { Specific activity } \\
\text { (mU/mg protein) }\end{array}$ & $\begin{array}{c}\text { Total activity } \\
\text { (U) }\end{array}$ & $\begin{array}{c}\text { Purification } \\
\text { (fold) }\end{array}$ \\
\hline $14.000 \times \mathrm{g}$ supernatant & 1520 & 14,24 & 21644 & 9,38 & 209,7 & 1 \\
\hline $\begin{array}{l}\text { 45\% Ammonium Sulphate } \\
\text { Fract. }\end{array}$ & 1670 & 11,76 & 19639 & 22,72 & 446,2 & 2,4 \\
\hline $\begin{array}{l}\text { 65\% Ammonium Sulphate } \\
\text { Fract. }\end{array}$ & 92.4 & 38,08 & 3518,59 & 70,16 & 246,86 & 7,47 \\
\hline G-25 Sephadex Column & 105 & 31,28 & 3284,4 & 36,304 & 119,24 & 3,87 \\
\hline Phosphocellulose Column & 6 & 1,904 & 11,424 & 590,94 & 67,5 & 63 \\
\hline
\end{tabular}


Pure enzyme samples were applied to SDS-PAGE electrophoresis for control of purity and in order to determine the molecular weight [29]. We demonstrated the purity of enzyme samples and also verified molecular weight of human placental aldolase is $160 \mathrm{kDa}$ identical with rabbit muscle aldolase (Fig. 2).

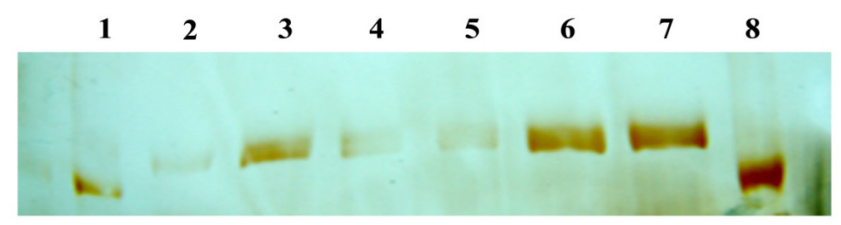

Figure 2. SDS-PAGE of healthy and gestational diabetic human placental aldolases.

Line 1 and 8: carbonic anhydrase,

Line 2 and 5: rabbit muscle aldolase,

Line 3 and 4: human placental aldolase (Applied (10 $\mu \mathrm{L})$, one sample per well),

Line 6 and 7: human placental aldolase (Applied $(20 \mu \mathrm{L})$, one sample per well)

The samples were run on a 7,5\% (w/v) acrylamide separating gel and a 4,5\% stacking gel. The subunit molecular mass was determined as $40 \mathrm{kDa}$. Therefore, it is observed that the human placental aldolase is a homotetramer (Fig. 3).

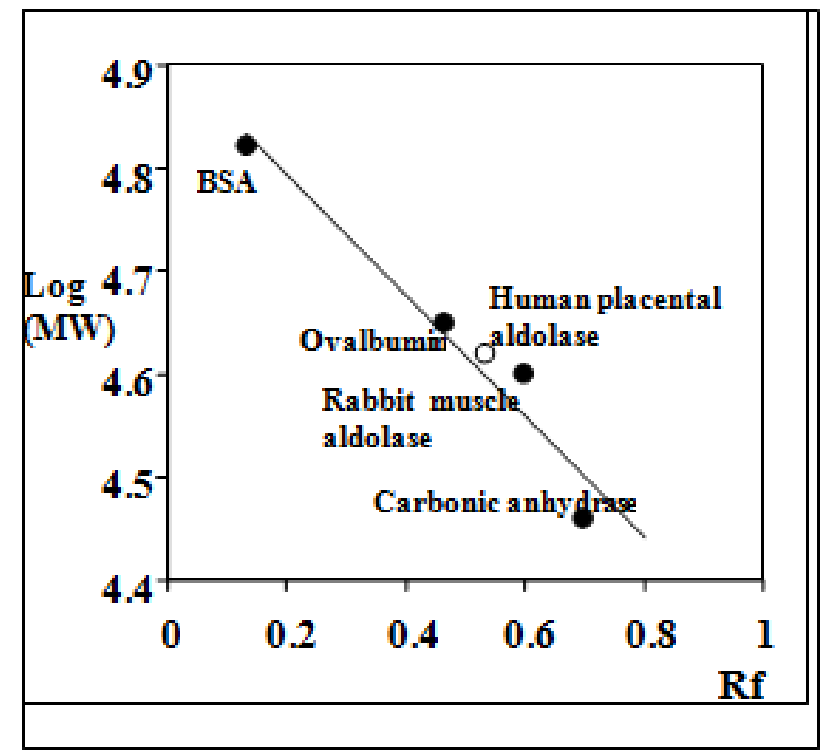

Figure 3. Molecular weight distribution of FBPA. Standard Rf-Log MW graph of aldolase from human placenta.

In this study, we also determined the optimal conditions $(\mathrm{pH}$, temperature, time) of the enzyme activity.

\section{1. pH Optimization}

The effect of $\mathrm{pH}$ on the aldolase activity was determined by using $50 \mathrm{mM}$ FBP with the following buffers $(50 \mathrm{mM})$ at the indicated $\mathrm{pH}$; acetate buffer $(\mathrm{pH} \mathrm{5,0}$ and 8,5), phosphate buffer ( $\mathrm{pH} \mathrm{6,0} \mathrm{and} \mathrm{6,5),} \mathrm{and} \mathrm{Tris-} \mathrm{HCl}$ buffer $(\mathrm{pH} 7,0-8,5)$. Then, the standard enzyme assay which was described previously was used. The optimum $\mathrm{pH}$ was determined as 7,4 . The acquired optimum $\mathrm{pH}$ was used to determine thermal properties and other parameters (data not shown).

\subsection{Optimization of Temperature}

To assess the optimum temperature, enzymatic assay was exercised between $10-60^{\circ} \mathrm{C}$. The optimum temperature was determined as $37{ }^{\circ} \mathrm{C}$ for the sample by measuring enzyme activities under standard assay conditions (data not shown).

\subsection{Optimal Incubation Time Determination}

In order to determine the optimum incubation duration, enzyme assay method was performed between 0-60 minutes, by 5 minutes increments at $37{ }^{\circ} \mathrm{C}$. The optimum incubation period was determined as 30 minutes under standard assay conditions (data not shown).

\subsection{Optimization of Hydrazone Stability Time}

To study the time stability of hydrazone formation, at the last stage of assay, the tubes were incubated for different periods of time at $37^{\circ} \mathrm{C}$. Enzyme activity was measured at 0 , $5,10,30,45$, and 60 th minutes, after formation of hydrazone. The optimum stability time was determined between 0-5 minutes for samples under standard assay conditions (data not shown).

\subsection{Substrate Kinetics of Gestational Diabetic Human Placental Aldolase}

According to our results, Vmax was determined as $939,548 \pm 60,869 \mathrm{U} / \mathrm{mg}$ and $\mathrm{Km}$ as $24,304 \pm 2,948 \mathrm{mM}$ for total substrate $0-60 \mathrm{mM}$ FBP concentrations.

The Michaelis-Menten equation means the relationship between the initial velocity and substrate concentration. A plot of V (velocity) vs. substrate (Michaelis-Menten plot) is hyperbolic for many enzymes [31]. The Michaelis-Menten plot for total substrate concentrations which describes the convenience between the initial velocity (Vo) and substrate concentrations is shown in Fig. 4.

In contrast to healthy human placental aldolase, the Michaelis-Menten diagram was not observed to have biphasic feature [26]. Because of the Michaelis-Menten plot was not seen with two phases and biphasic constitution, there was no need to draw new diagrams for low and high concentrations of substrate. 


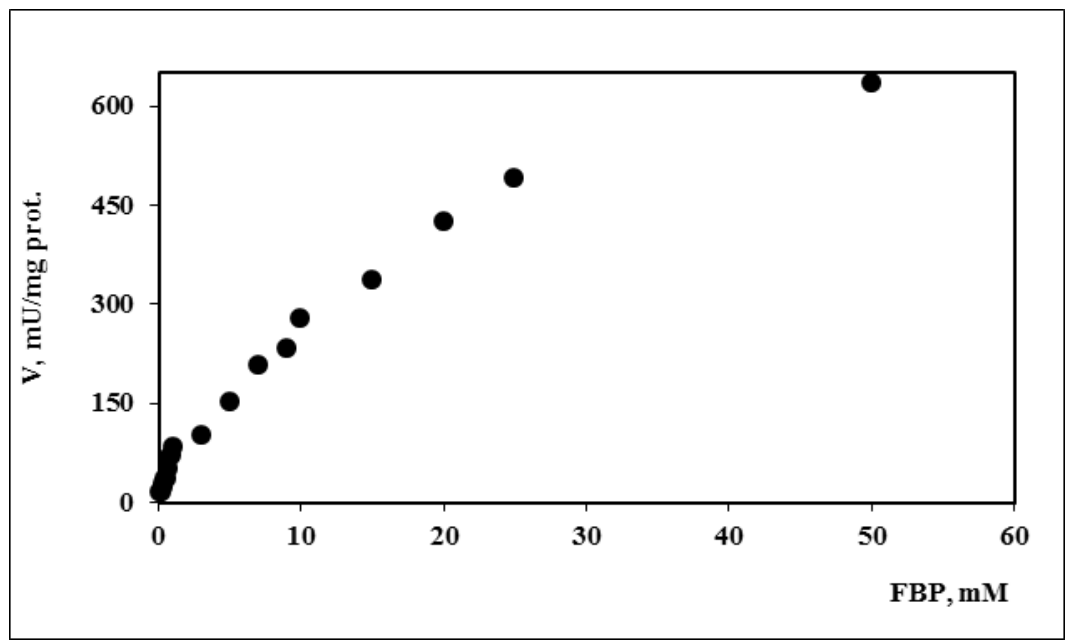

Figure 4. Effect of total FBP concentrations on gestational diabetic human placental FBPA (Michaelis-Menten Plot for FBP)

The Lineweaver-Burk (LB) plot, which is associated with total FBP concentrations for gestational diabetic placental fructose 1,6 bisphosphate aldolase (FBPA), is shown at Fig. 5. Lineweaver Burk plot appears to be nonlinear and appropriate to negative cooperativity [31]. It was observed that LB diagram line of total substrate concentrations appears to be downwards. New LB diagrams were performed for the phases that separated from this point.

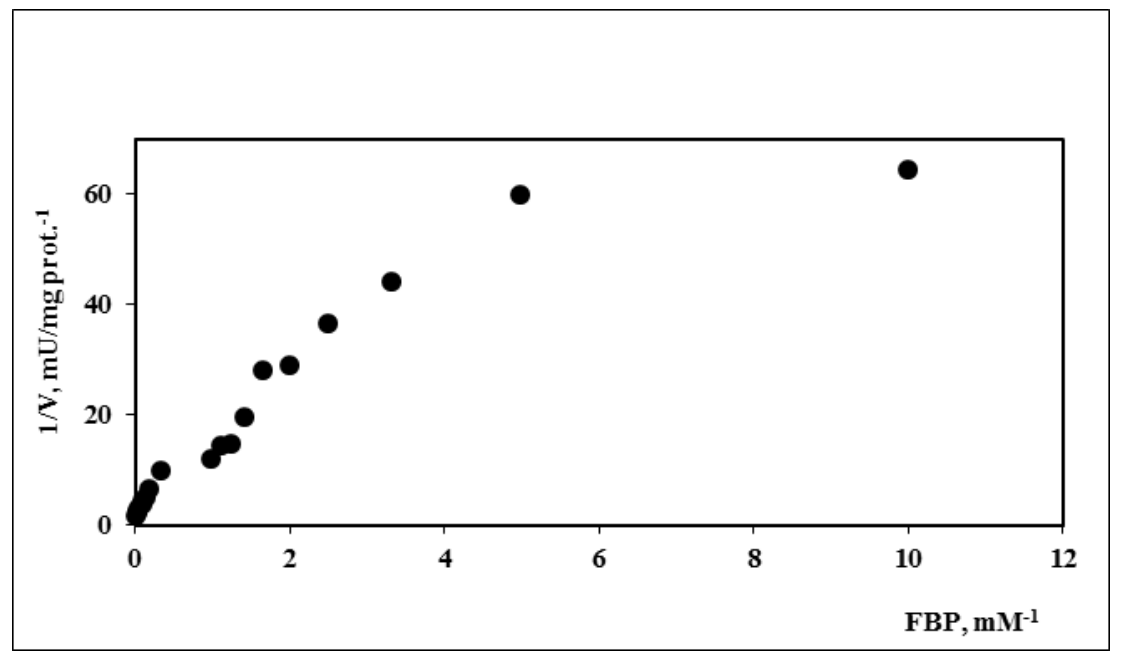

Figure 5. Lineweaver-Burk plot of effect of total FBP concentrations on GDM human placental FBPA

We found two distinct $\mathrm{Km}$ values of low and high concentrations of FBP on gestational diabetic aldolase. Lineweaver-Burk diagram shows that the enzyme that was purified from diabetic placenta is not completely biphasic characteristic. 


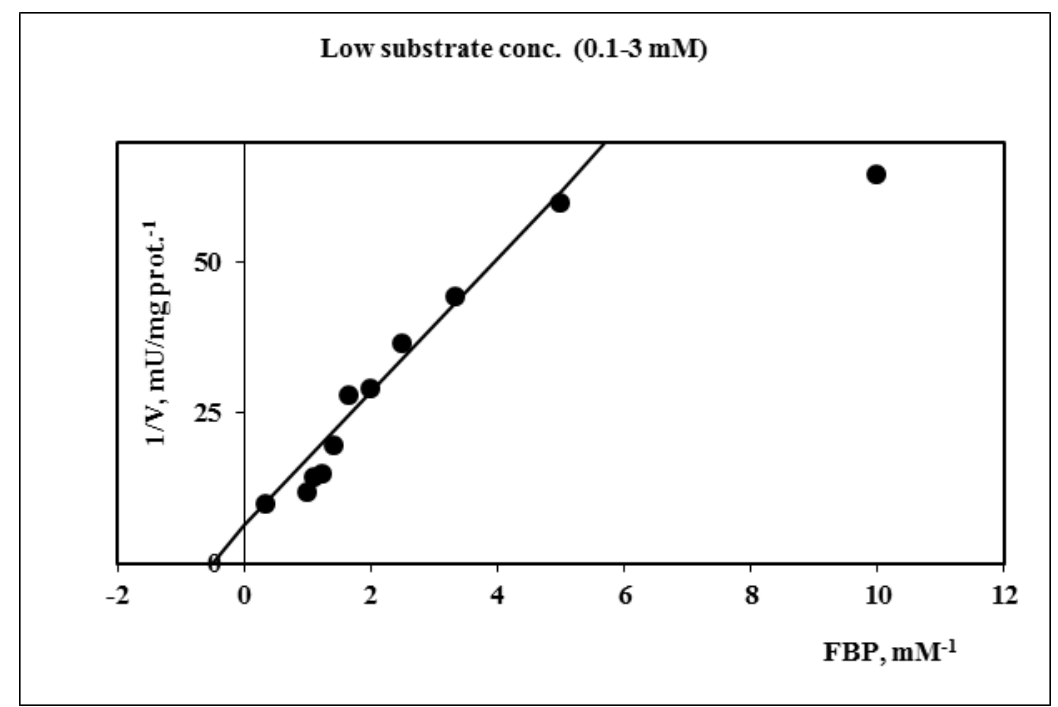

Figure 6. Effect of low FBP concentrations $(0,1-3 \mathrm{mM})$ on GDM human placental FBPA (Lineweaver-Burk diagram for 0,1-3 mM FBP)

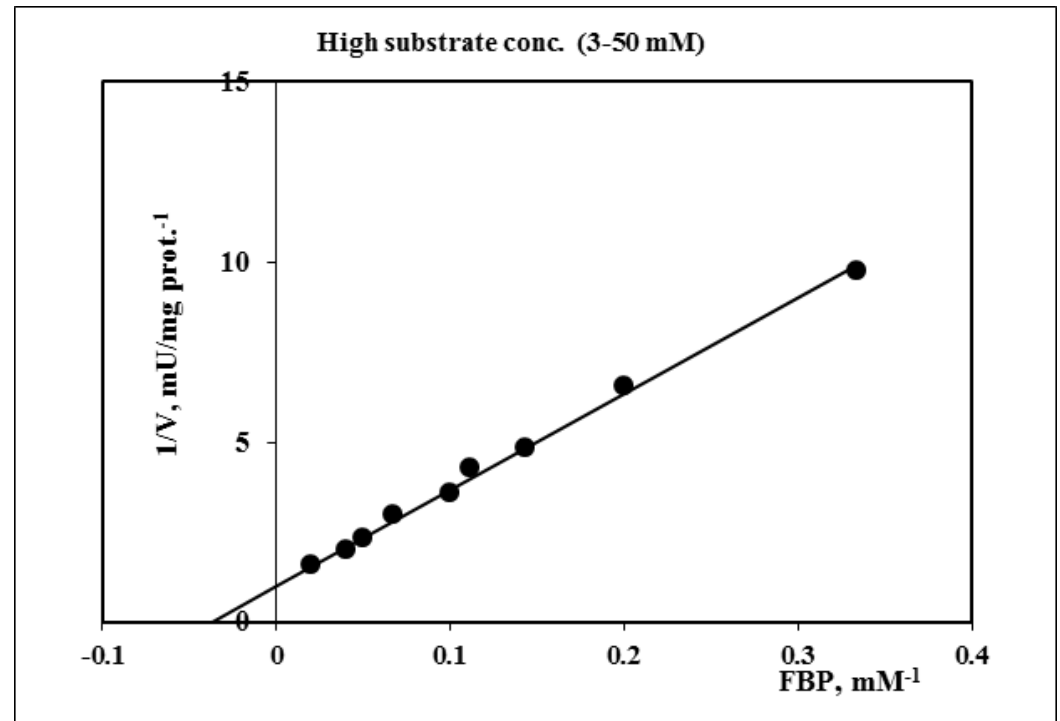

Figure 7. Effect of high FBP concentrations on GDM human placental FBPA (Lineweaver-Burk diagram for 3-50 mM FBP)

At low concentrations of substrate $(0,1-3,0 \mathrm{mM})$, the value of $\mathrm{Km}$ of diabetic placental aldolase was determined as $1,385 \pm 0,403 \mathrm{mM}$, and the value of Vmax was determined as $159,422 \pm 26,180 \mathrm{mU} / \mathrm{mg}$ (Fig. 6). At high concentrations of substrate, Vmax and $\mathrm{Km}$ were defined as $981,093 \pm 38,483$ $\mathrm{mU} / \mathrm{mg}$ and $26,686 \pm 1,913 \mathrm{mM}$ respectively, as pointed out in Fig.7.

In accordance with the present graphics, high substrate concentration range $(3-50 \mathrm{mM})$ is determined as the linear substrate concentration zone. Therefore, advanced kinetic studies will be performed at this linear zone.

Hill plot was graphed to understand this manner thoroughly, which was related to the concentrations of substrate of FBPA. At Hill plot diagram, it's found out that gestational diabetic human placental aldolase does not have biphasic feature (Fig. 8).

With reference to Hill plot, it is observed that gestational diabetic FBPA does not display diverse properties with different substrate concentrations, contrary to healthy human placental aldolase [26].

However, we obtained two different $\mathrm{Km}$ values for diabetic human placental aldolase. This situation was displayed previously in LB diagrams. As mentioned before, while high substrate concentrations of $\mathrm{Km}$ were $26,686 \pm 1,913 \mathrm{mM}$, low concentrations of $\mathrm{Km}$ were found as $1,385 \pm 0,403 \mathrm{mM}$ according to LB plot. 


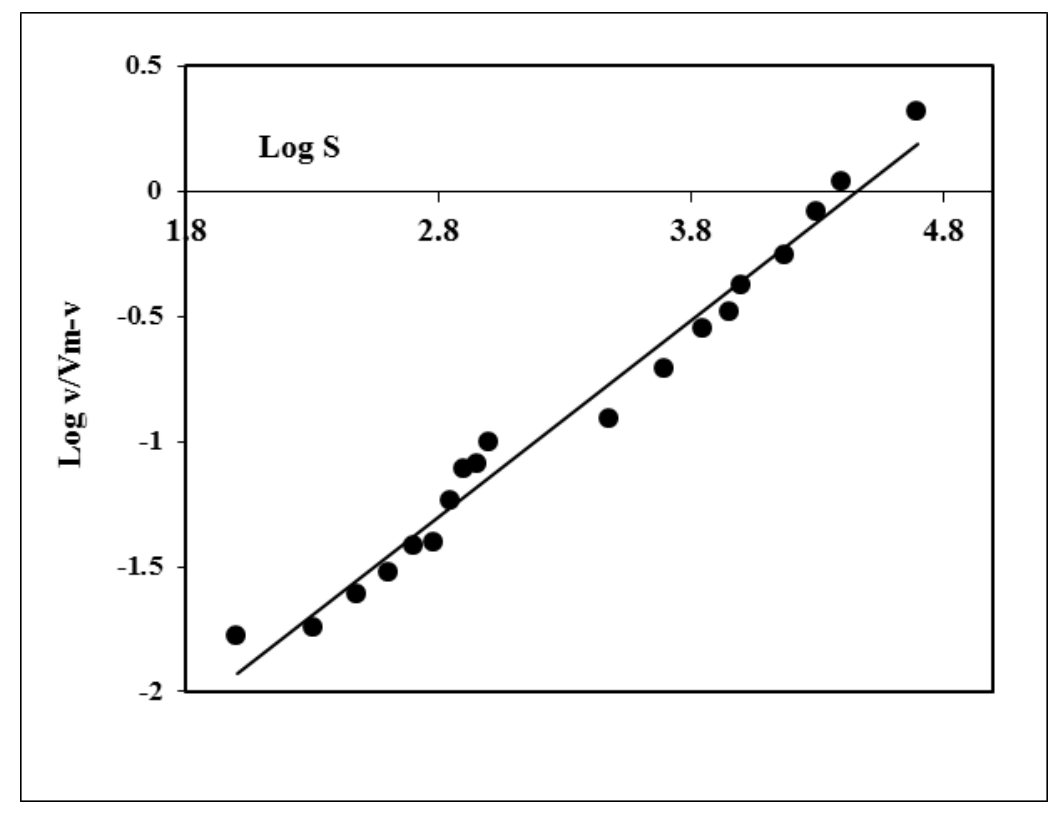

Figure 8. Hill plot of GDM human placental aldolase for total substrate concentrations

\section{Discussion}

In our preceding study, we demonstrated the presence of aldolase, then purified and investigated the substrate kinetic properties of healthy human placental aldolase [26]. In the present study, our main goal was to investigate the roles of the enzyme in changes observed in GDM. With the procedure determined in this study, [32], aldolase was purified 63,0 fold from gestational diabetic human placenta. Until now, there is no knowledge in literature about the presence and purification of aldolase particularly from gestational diabetic human placenta.

The different steps of purification of placental aldolase are summarized in Table 1. Phosphocellulose elution graphic of the enzyme is shown in Fig. 1.

SDS-Page electrophoresis provided a single pure band when the pure enzyme was subjected to electrophoresis (Fig. 2 ). The band was found to migrate identically with rabbit muscle aldolase under identical conditions. As a result of electrophoretic tests, it was determined that molecular weight of human placental aldolase is $160 \mathrm{kDa}$ and the enzyme is homotetramer and similar to rabbit muscle (Fig. 3).

After temperature, $\mathrm{pH}$, and time optimizations were performed for placental aldolase, it was observed that the optimum $\mathrm{pH}$ was 7,4, and temperature was $37^{\circ} \mathrm{C}$. Additionally, incubation and hydrazone stability duration of enzymes were optimized. Aldolases, particularly Class I, are crucial enzymes in glycolysis. Aldolase enzymes are subjects under investigation with regard to their substrate cleavage mechanisms. FBPA has been investigated in many tissues [4,7,10-13].

In this research, gestational diabetic human placental enzyme was purified with the modified method based on Penhoet [32]. Placental aldolase was eluted with substrate bounding to column. We found that the specific activity of the diabetic enzyme was $590,94 \mathrm{mU} / \mathrm{mg}$ protein. Similar to the previous study with healthy human placental aldolase [26], two pure separate peaks were determined at elution graphic profiles. We believe that this difference from model literature is characteristic of placental aldolase.

In the present study, we also investigated some kinetic properties of gestational diabetic placental enzyme thoroughly.

In contrast to healthy human placental aldolase, the Michaelis-Menten plot (Fig. 4) was seen with one phase for gestational diabetic human placental aldolase [26]. Because the Michaelis-Menten plot was single phase and not observed to have biphasic constitution, there was no need to draw new diagrams for low and high concentrations of the substrate. It's conceived that the different kinetic behaviours of both enzymes forms result from diabetic deformational complications on tissue. Although there were no differences between the electrophoretic analyses of both enzymes, it's deemed that the activity may have been affected by absence or difference of any amino acid which is located in active side of the enzyme. Hence, we estimate that general effect of gestational diabetes mellitus may occur in this direction on the enzyme.

According to the Lineweaver-Burk (LB) plot associated with total FBP concentrations, Vmax was 939,548 $\pm 60,869$ $\mathrm{U} / \mathrm{mg}$, and $\mathrm{Km}$ was $24,304 \pm 2,948 \mathrm{mM}$ for gestational diabetic human placental FBPA. The LB plots seemed to be nonlinear and appropriate to negative cooperativity [31]. It was found that LB diagram line of total substrate concentrations appeared to be downwards. New LB diagrams were performed for the phases that separated from this point. High substrate concentration range $(3-50 \mathrm{mM})$ has been determined as linear substrate concentration zone.

It was detected that $\mathrm{Km}$ value was about $24 \mathrm{mM}$ for 
fructose 1,6-bisphosphate in the present study. The apparent catalytic parameters of class I FBP aldolases have wide variations. The calculated $\mathrm{Km}$ values of characterized class I; aldolase A from human muscle is $52 \mu \mathrm{M}$, liver type aldolase $\mathrm{B}$ is $1,6 \mu \mathrm{M}$, and brain type aldolase $\mathrm{C}$ is $10,7 \mu \mathrm{M}$ for fructose 1,6-bisphosphate [4,33].

Similar to our previous study, the most remarkable part of this research was to observe two different $\mathrm{Km}$ and Vmax values at high and low concentrations of substrate Fructose 1,6-bisphosphate. Hill plot of gestational diabetic placental aldolase supports that enzyme points out different kinetic features for varied substrate concentrations. When two Km values were compared with each other, it is determined that the affinity of the enzyme with its substrate increases when the concentration of fructose 1,6-bisphosphate is low. It seems that fructose 1,6-bisphosphate aldolase is an important enzyme of glycolysis and energy metabolism for placental cells.

It is estimated that there may be a modification in the enzyme structure of placental cells for low concentrations of fructose 1,6-bisphosphate. Previous studies showed that human muscle, liver, and brain type aldolases have monophasic character for fructose 1,6-bisphosphate [4,12]. Because of that, this unprecedented situation seems to be characteristic for placental aldolases. Based on this finding, we can conclude that the amino acid sequences, active sites, and kinetic characteristics of aldolases can be different in various tissues.

It is considered that placental structure and function can change as a result of maternal diabetes. Maternal and foetal concentrations of several growth factors, hormones, and cytokines are altered in diabetes and may affect the placenta and the fetal development. It is thus necessary to identify the specific biological effects and the mechanisms underlying them [25].

Diabetes-associated changes are likely to affect the placenta because enzymes, receptors, and transporters, the primary targets of circulating molecules, are expressed, often asymmetrically, on both placental surfaces [24].

In the existing study, we found a lower specific activity than the healthy placental enzyme [26]. Relying on the experimental data, we supposed that activity differentials originate from the diabetic complications. It may be concluded that differences of amounts and activity of aldolase may be a responsible factor in diabetic complications when compared with the previous research. It's predicted that the reduction of enzymatic activity of diabetic tissue may result from diabetic tissue damage. It's thought that this difference occurs because of some conformational defects on enzyme due to diabetes. It's known that the enzyme activity of the aldolase decreases in lots of metabolic disorders [34]. By all means, it can be said that diabetes also causes some damages on placenta tissue which effect the enzyme activity negatively $[33,35]$.

It is known that all defined aldolase isozymes have strictly conserved residues in the active site consisting of Asp33, Arg42, Lys107, Lys146, Glu187, Ser271, Arg303, and
Lys229 (which forms the Schiff-base intermediate). They are immunochemically distinct and have different catalytic properties, such as the ratio of the specificity constants (kcat/Km) [4].

As mentioned before, in this study, our main purpose was clarified the differences of the enzyme activities between healthy and gestational diabetic FBPA. And we were purified, and investigated the kinetic properties of gestational diabetic human placental FBPA. The main purpose of the study is not clinical investigation. This study is focused on the enzyme activity.

In the present and former studies, we could not define the amino acid sequences and active sites of placental aldolases. Further studies are under consideration about the kinetic properties of inhibitors of both healthy and diabetic human placental aldolases. We believe that determination of inhibition kinetic features of placental aldolase will supply more information to understand the differences between other tissues and placental aldolases. These kinetic properties will clarify the characterization of enzyme structure.

\section{Acknowledgements}

This work is a part of the project (05.T06.101.001) supported by scientific research unit of Hacettepe University.

\section{REFERENCES}

[1] J. A. Littlechild, H.C. Watson, A data-based reaction mechanism for type I fructose bisphosphate aldolase, TIBS, 8, 36-39, 1993.

[2] S. J. Gamblin, G.J. Davies, R.M. Jackson, J.A. Littlechild, and H.C. Watson, Activity and specificity of human aldolases, J Mol Biol., 219, 573-576, 1991.

[3] K. H. Choi, D. R. Tolan, Presteady-state kinetic evidence for a ring opening activity in fructose-1,6 (bis)phosphate aldolase, JACS, 126, 3402-3403, 2004.

[4] T. L. Arakaki, J.A. Pezza, M.A. Cronin, C.E. Hopkins, D.B. Zimmer, D.R. Tolan, and K.N. Allen, Structure of human brain fructose 1,6-(bis)phosphate aldolase: Linking isozyme structure with function, Protein Science, 13, 3077-3084, 2004.

[5] M. Sherawat, D.R. Tolan, K.N. Allen, Structure of a rabbit muscle fructose-1,6-bisphosphate aldolase A dimer variant, Acta Crystallogr. D Biol Crystallogr., 64, 543-550, 2008.

[6] V. Sauvé, J. Sygusch, Crystallization and preliminary X-ray analysis of native and selenomethionine fructose-1,6-bispho sphate aldolase from Thermus aquaticus, Acta Crystallogr D Biol Crystallography, 57, 310-313, 2001.

[7] W.J. Rutter, Evolution of aldolase, Fed Proc., 23, 1248-1257, 1964. 
[8] G.C. Capodagli, W.G. Sedhom, M. Jackson, K.A. Ahrendt, and S.D. Pegan, A Noncompetitive Inhibitor for Mycobacterium tuberculosis's Class IIa Fructose 1,6-Bisphosphate Aldolase, Biochemistry, 53, 202-213, 2014.

[9] K. Nakahara, H. Yamamoto, C. Miyake, A. Yokota, Purification and Characterization of Class-I and Class-II Fructose-1,6-bisphosphate Aldolases from the Cyanobacterium Synechocystis sp. PCC 6803, Plant Cell Physiol., 44, 326-333, 2003.

[10] G.J. Thomson, G.J. Howlett, A.E. Ashcroft, A. Berry, The dhnA gene of Escherichia coli encodes a class I fructose bisphosphate aldolase, Biochem. J., 331, 437-445, 1998.

[11] M.Y. Galperin, L. Aravind, E.V. Konin, Aldolases of the DhnA family: a possible solution to the problem of pentose and hexose biosynthesis in archaea, FEMS Microbiol Lett., $183,259-264,2000$.

[12] L. Esben, S. Bettina, H. Reinhard, and P. Ehmke, Mechanism of the Schiff Base Forming Fructose-1,6-bisphosphate Aldolase: Structural Analysis of Reaction Intermediates, Biochemistry. 44, 4222-4229, 2005.

[13] F. Salvatore, P. Izzo, G. Paolella, Aldolase gene and protein families: structure, expression and pathophysiology, In Horizons in Biochemistry Biophysics (Blasi, F, ed.), 8, 611-665, 1986

[14] D.T.D. Osmond, C.J. Nolan, R.G. King, S.P. Brennecke, N.M. Gude, Effects of gestational diabetes on human placental glucose uptake, transfer, and utilisation, Diabetologia, 43, 576-582, 2000.

[15] [15] B.E. Metzger, D.R. Coustan, Proceedings of the Fourth International Workshop-Conference on Gestational Diabetes Mellitus, Diabetes Care, 21, B1-B167, 1998.

[16] D. Gernot, H. Sylvie, The Human Placenta in Gestational Diabetes Mellitus, Diabetes Care, 30, 120-126, 2007.

[17] T.A. Buchanan and A.H. Xiang, Gestational diabetes mellitus, The Journal of Clinical Investigation, 115, 485-491, 2005.

[18] T.A. Hillier, K.K. Vesco, K.L. Pedula, T.L. Beil, E.P. Whitlock, and D.J. Pettitt, Screening for Gestational Diabetes Mellitus: A Systematic Review for the U.S. Preventive Services Task Force, Ann Intern Med., 148, 766-775, 2008.

[19] T.A. Buchanan, A.H. Xiang, Gestational diabetes mellitus, The Journal of Clinical Investigation. 115, 485-491, 2005.

[20] J.M. Perkins, J.P. Dunn, and S.M. Jagasia, Perspectives in Gestational Diabetes Mellitus: A Review of Screening,
Diagnosis, and Treatment, Clinical Diabetes, 25, 57-62, 2007.

[21] C. Kim, Gestational diabetes: risks, management, and treatment options, International Journal of Women's Health, 2, 339-351, 2010.

[22] M. Gauster, G. Desoye, M. Tötsch, U. Hiden, The Placenta and Gestational Diabetes Mellitus, Curr Diab. Rep., 12, 16-23, 2012.

[23] T.A. Buchanan, A.H. Xiang, K.A. Page, Gestational diabetes mellitus: risks and management during and after pregnancy, Nature Reviews Endocrinology, 8, 639-649, 2012.

[24] U. Hiden, G. Desoye, The placenta in a diabetic pregnancy, J. Reproduktionmed. Endokrinol., 7, 27-33, 2010.

[25] A. Vambergue, I. Fajardy, Consequences of gestational and pregestational diabetes on placental function and birth weight, World J Diabetes, 2, 96-203, 2011.

[26] N. H. Aksoy and P. Dogan, Purification, characterization and some kinetic properties of fructose 1,6 bisphosphate aldolase from human placenta, Yeditepe Medical Journal, 11, 190-202, 2009.

[27] O.H. Lowry, et al, Protein measurement with the folin phenol reagaent, J Biol Chem., 193, 265-275, 1951.

[28] V.C. Pinto, P.A. Van Dreal, A. Kaplan, Aldolase: Colorimetric and spectrophotometric determination, Clin Chem., 15, 339-360, 1969.

[29] U.K. Laemli, Cleavage of structural proteins during the assembly of the head of bacterophage T4, Nature, 227, 680-685, 1970.

[30] O. Warburg, W. Christian, Isolation and crystallization of enolase, Biochem Z., 310, 384-421, 1942.

[31] I. H. Segel, Enzyme Kinetics: A Wiley-Interscience Publication, New York, pp. 353-379, 1975.

[32] E.E. Penhoet, and W.J. Rutter, Detection and isolation of mammalian fructose bisphosphate aldolase, Methods in enzymology, 42, 240-249, 1975.

[33] C.A. Burtis and E. R. Ashwood, Tietz Text Book of Clinical Chemistry, pp. 776, 810-812, 2107-2108, 1994.

[34] D. Voet and J.G. Voet, Biochemistry, Wiley Pres, Chapter 16, pp. 450-53, 1995.

[35] R. Gitzelman, et al., Disorders of fructose metabolism. In the metabolic basis of inherited disease, McGraw Hill, New York, pp. 905-934, 1995. 